IZA DP No. 6109

Heterogeneous Firms, Trade, and Economic Policy: Insights from a Simple Two-Sector Model

Michael Pflüger

Stephan Russek

November 2011 


\title{
Heterogeneous Firms, Trade, and Economic Policy: Insights from a Simple Two-Sector Model
}

\author{
Michael Pflüger \\ University of Passau, \\ DIW Berlin and IZA \\ Stephan Russek \\ University of Passau
}

\author{
Discussion Paper No. 6109 \\ November 2011
}

\author{
IZA \\ P.O. Box 7240 \\ 53072 Bonn \\ Germany \\ Phone: +49-228-3894-0 \\ Fax: +49-228-3894-180 \\ E-mail: iza@iza.org
}

\begin{abstract}
Any opinions expressed here are those of the author(s) and not those of IZA. Research published in this series may include views on policy, but the institute itself takes no institutional policy positions.

The Institute for the Study of Labor (IZA) in Bonn is a local and virtual international research center and a place of communication between science, politics and business. IZA is an independent nonprofit organization supported by Deutsche Post Foundation. The center is associated with the University of Bonn and offers a stimulating research environment through its international network, workshops and conferences, data service, project support, research visits and doctoral program. IZA engages in (i) original and internationally competitive research in all fields of labor economics, (ii) development of policy concepts, and (iii) dissemination of research results and concepts to the interested public.
\end{abstract}

IZA Discussion Papers often represent preliminary work and are circulated to encourage discussion. Citation of such a paper should account for its provisional character. A revised version may be available directly from the author. 


\section{ABSTRACT \\ Heterogeneous Firms, Trade, and Economic Policy: Insights from a Simple Two-Sector Model ${ }^{*}$}

The robust empirical finding that exporting firms are systematically different from firms that merely serve domestic consumers has inspired the development of a new brand of trade theory, the theory of heterogeneous firms and trade. The establishment of a canonical model due to Melitz (2003) has induced a recent wave of research which explores various policy issues and policy instruments. This paper uses a simple tractable two-sector model of monopolistic competition as unifying framework to bring out key lessons of this recent research. We address the gains from trade, country asymmetries involving technology potentials, market sizes, trade openness and various business conditions as well as the international repercussions that emerge when countries non-cooperatively choose entry subsidies and their levels of basic research. We also reinvestigate the process of market exit.

JEL Classification: F12, F13, F15, L25

Keywords: firm heterogeneity, monopolistic competition, economic policies and welfare

Corresponding author:

Michael Pflüger

Faculty of Economics

University of Passau

Innstrasse 27

94032 Passau

Germany

E-mail: michael.pflueger@uni-passau.de

\footnotetext{
* We would like to thank the organizers and participants of the CESifo Venice Summer Institute 2011 Workshop "Globalisation, Trade, FDI and the Multinational Firm" for helpful comments. We would also like to thank Rainald Borck, Svetlana Demidova, Philipp Schröder, Jens Südekum, Zhihong Yu and participants of workshops and conferences in Nottingham (GEP), Aarhus (School of Business), Glasgow (EEA) and Lausanne (ETSG) for their stimulating comments.
} 


\section{Introduction}

The robust empirical finding that exporting firms are not only rare but also systematically different from firms that merely serve domestic consumers has challenged both the old Ricardian and neoclassical trade theories as well as the new trade theories along the lines of Krugman, Brander and Spencer. To account for the empirical fact that exporting firms are typically larger and more productive than non-exporters, a new generation of new trade models was developed which takes the heterogeneity of firms in terms of their productivity into account with seminar contributions by Melitz (2003), Bernard, Eaton, Jensen and Kortum (2003) and Yeaple (2005). ${ }^{1}$ Follow-up research led to a voluminous literature that expanded the scope of these theories of heterogeneous firms and trade to comprehend endowment-driven comparative advantage (Bernard, Redding and Schott 2007), competition effects (Melitz and Ottaviano 2008) and the repercussions between trade, FDI and labor markets, amongst others. ${ }^{2}$

A very recent strand of research has started to explore the economic policy implications of the theories of heterogeneous firms and trade. Melitz (2003) has initiated this policy analysis by showing that countries reap welfare gains by shifting from autarky to trade (i.e. there are gains from trade) and by proving that reciprocal trade liberalization is welfare enhancing for all parties. However, his analysis was confined to a setting where countries are identical in all respects. Yet, countries do differ along many dimensions, such as size, technologies and a variety of other business conditions, in practice. Can we be sure that his insights still hold when country asymmetries are taken into account? It is comforting to see that recent research has shown the gains from trade to be robust when countries are (strongly) asymmetric in many dimensions that have so far been put under scrutiny. However, recent work also conveys the message that matters may be different when countries already engage in trade. Technological improvements in one country's modern sector then unambiguously hurt the trading partner. When business conditions in a broad sense are superior in one country, trade liberalization brings a welfare benefit to the superior country whereas the inferior country may experience a welfare loss. Moreover, it has also been shown that the liberalization path matters, i.e. it makes a big difference whether liberalization is unilateral or reciprocal.

Further important policy questions have been addressed in recent work. One strand of research recognizes that governments are heavily engaged in the regulation of entry by requiring licences,

\footnotetext{
${ }^{1}$ Bernard, Jensen, Redding and Schott (2007) and Mayer and Ottaviano (2007) summarize the empirical work.

${ }^{2}$ Examples of the labor market applications are Eckel and Egger (2009), Egger and Kreickemeier (2009), Felbermayr et al. (2010), Helpman and Itskhoki (2010) and Helpman, Itskhoki and Redding (2010). Chor (2009) analyses FDI subsidies. Helpman (2006) and Redding (2010) provide surveys of the development of the theories of heterogeneous firms and trade.
} 
permits and other legal barriers. On the other hand, they also provide various types of support for the foundation of new firms, e.g. subsidies to market entry and R\&D activities. Interestingly, in contrast to classical trade policy instruments (such as import tariffs or export subsidies) these policies are perceived as largely domestic issues and therefore not put under scrutiny by bodies like the WTO. It is nonetheless important to ask whether these policies have international repercussions and how they play out. Recent research shows that such policies indeed involve international spillovers and that governments therefore may have an incentive to use these instruments strategically in the open economy.

The process of market exit is yet another issue which has received attention recently. Melitz (2003) focused on a stationary equilibrium where firms die with a constant probability irrespectively of their productivity and are replaced by new entrants. However, there is overwhelming empirical evidence that highly productive firms are much less prone to firm death than unproductive ones. Incorporating this fact into a theoretical framework delivers insights for the average death rates of mature firms and their determinants. For example, the switch from autarky to trade implies not only an increase in the average productivity of firms but also a reduction in the risk of business exit.

The aim of this paper is to work out and synthesize the key lessons of this recent research in a unifying framework. To bring these results out with utmost simplicity, we use a two-sector version of the Melitz (2003) model with a competitive sector ('traditional good') in addition to the monopolistically competitive sector with heterogeneous firms ('modern sector'). The fruitfulness of this modelling strategy was already convincingly demonstrated by Helpman and Krugman $(1985 ; 1989)$ in exposing the policy implications of the new trade theory with homogeneous firms. ${ }^{3}$ The seminal papers by Melitz and Ottaviano (2009) and Demidova (2008) were the first contributions which adopted two-sector frameworks to analyze the implications of the theories of heterogeneous firms and trade. Our synthesis follows Demidova (2008) in choosing a CES-Dixit-Stiglitz (1977) representation of the modern sector. We deviate from her by assuming a simple yet standard specification of the research and development process and by working with a simpler, quasi-linear, upper tier utility function. These two changes allow us to gain considerable tractability. In particular, we are able to provide all results in closed-form.

Melitz and Ottaviano (2008) provide an alternative two-sector model of monopolistic competition with heterogeneous firms which, by the assumption of a quadratic quasi-linear upper tier utility function, is already much more tractable than the one-sector Melitz (2003)

\footnotetext{
${ }^{3}$ See also Flam and Helpman (1987), Venables (1987), Martin and Rogers (1995) and Baldwin et al. (2003).
} 
model. ${ }^{4}$ Rather than using the Dixit-Stiglitz specification of the modern sector, Melitz and Ottaviano (2008) employ the linear demand system with horizontal product differentiation along the lines of Ottaviano, Tabuchi and Thisse (2002). In contrast to the Dixit-Stiglitz framework which implies that mark-ups over marginal costs are constant across firms and invariant to market size in the large-group case the linear Ottaviano-Tabuchi-Thisse-framework features a pro-competitive effect. This feature renders the latter framework without any doubt attractive. However, as many of the recent papers have used the Dixit-Stiglitz-specification as in Melitz (2003), we use the same as it facilitates the exposition and discussion of these works.

The structure of the paper is as follows. The next section covers the model under autarky. Section 3 discusses a two country trade version of the model. Section 4 contains our policy analysis. We cover gains from trade, trade liberalization with identical countries, the implications of differences in technology potentials, the competitive choice of entry subsidies and of policies targeted the infrastructure of basic research, the implications of business conditions along many dimensions, and the process of market exit. Section 5 concludes.

\section{The Model}

General set-up. We build on the two-sector version of the Melitz (2003) model with heterogeneous firms developed by Demidova (2008). A traditional industry $n$ produces a homogeneous numéraire good under constant returns to scale and perfect competition, and a modern monopolistic competitive industry $c$ produces a continuum of differentiated varieties under increasing returns. Each variety is produced by a single firm. Firms' productivities are heterogeneous. Labor is the only factor of production in the economy. There are $L$ workers who supply one unit of labor each. We first look at a single country in autarky.

Preferences. Household $h$ 's preferences over the homogenous good $n^{h}$ and the set of modern varieties, $\Omega$, are defined by a logarithmic quasi-linear utility function with CES sub-utility $c^{h 5}$

$$
u^{h}=\beta \ln c^{h}+n^{h} \quad c^{h}=\left[\int_{z \in \Omega} q^{h}(z)^{\rho} d z\right]^{1 / \rho}
$$

where $0<\rho<1$ and $\beta>0$ are constant parameters and $q^{h}(z)$ expresses $h$ 's consumption of variety $z$. The elasticity of substitution between any two varieties is given by $\sigma \equiv 1 /(1-\rho)>1$.

\footnotetext{
${ }^{4}$ An extension and calibration of the Melitz-Ottaviano model is provided in Del Gatto et al. (2006).

${ }^{5}$ We deviate from Demidova (2008) who assumes Cobb-Douglas preferences. Quasi-linear preferences remove the income effect from the modern sector. They are widely used in theories of geography and trade because of their tractabilty (e.g. Ottaviano, Tabuchi and Thisse 2002, Antras and Helpman 2004 and Melitz and Ottaviano 2008).
} 
The budget constraint reads $P c^{h}+n^{h}=w$ where $w$ is $h$ 's (wage) income and

$$
P=\left[\int_{z \in \Omega} p(z)^{1-\sigma} d z\right]^{\frac{1}{1-\sigma}}
$$

is the perfect price index of the CES-aggregate. Utility maximization implies demand functions $c^{h}=\beta / P$ for the modern good and $n^{h}=w-\beta$ for the traditional good, respectively. Household $h$ 's indirect utility is $v^{h}=w-\beta \ln P+\beta(\ln \beta-1)$. Since households are identical we drop the index $h$ from now on. We assume $\beta<w$ to ensure non-negative demand for the homogeneous good. Aggregation over households implies that the overall expenditure on the modern industry, $P c L$, equals $\beta L$. Aggregate demand for variety $z$ is $q(z)=p(z)^{-\sigma} P^{\sigma-1} \beta L$, and total revenue for that variety is $r(z)=p(z) q(z)=[P / p(z)]^{\sigma-1} \beta L$.

Technology and pricing. The numéraire-sector transforms $a$ units of labor into one unit of output. The wage is then pinned down at $w=1 / a$. Technologies in the modern sector are such that $l=f+q / \varphi$ units of labor are needed to produce $q$ units of output. The fixed overhead labor $f$ is the same for all firms, the variable labor requirement $(1 / \varphi)$ differs across firms. We consider the case where firms have zero mass. Each firm then perceives a demand curve with constant price elasticity $-\sigma$. Profit maximization implies that a firm with marginal $\operatorname{cost}(w / \varphi)$ charges the price:

$$
p(\varphi)=\frac{w}{\rho \varphi}
$$

where $\rho \equiv(\sigma-1) / \sigma$. Revenue and profits of this firm are then given by $r(\varphi)=\beta L(\rho \varphi P / w)^{\sigma-1}$ and $\pi=r(\varphi) / \sigma-w f$, respectively. A firm with higher productivity level $\varphi$ thus charges a lower price, sells a larger quantity and has higher revenue and profits. Since all firm-specific variables differ only with respect to $\varphi$, the CES price index (2) can be rewritten as

$$
P=M^{1 /(1-\sigma)} p(\tilde{\varphi})=M^{1 /(1-\sigma)} \frac{w}{\rho \tilde{\varphi}} \quad \text { with } \tilde{\varphi} \equiv\left[\int_{0}^{\infty} \varphi^{\sigma-1} \cdot \mu(\varphi) d \varphi\right]^{1 /(\sigma-1)}
$$

where $M$ denotes the mass of manufacturing firms (and varieties) in the market, $\mu(\varphi)$ is the productivity distribution across these active firms with positive support over a subset of $(0, \infty)$ and $\widetilde{\varphi}$ is an average productivity level as introduced by Melitz (2003).

Entry and exit. There exists a mass of potential entrepreneurs who can enter the modern sector, once they incur an up-front investment of $f_{e}$ units of labor. At each point in time a mass of $M^{E}$ 
entrepreneurs decides to enter. Upon entry these entrepreneurs learn about their productivity $\varphi$, which is drawn from a common and known distribution function $G(\varphi)$ with support $(0, \infty)$ and density $g(\varphi)$. This is termed the 'productivity lottery'. After the productivity is revealed, an entrant decides whether to exit immediately or to remain active in the market, in which case the firm earns constant per-period profits $\pi(\varphi)$. It will exit immediately if $\pi(\varphi)<0$, i.e. $r(\varphi)<\sigma w f$. Hence, only those firms remain active whose productivity draw exceeds the cutoff $\varphi^{*}>0$ at which profits are zero, $\pi\left(\varphi^{*}\right)=0$. Once in the market, every firm may be hit with constant probability $\delta$ by a negative shock which forces it to shut down and exit. We focus on a stationary equilibrium without time discounting such that in each period the mass of market entrants equals the mass of firms that are forced to shut down. Analytically, $\operatorname{prob}_{i} M^{E}=\delta M$, where $\operatorname{prob}_{i} \equiv 1-G\left(\varphi^{*}\right)$ is the probability to draw a productivity no smaller than the cutoff $\varphi^{*}$. The endogenous productivity distribution among surviving firms, $\mu(\varphi)$, is thus the conditional (left-truncated) ex-ante distribution $g\left(\varphi^{*}\right)$ on the domain $\left\lfloor\varphi^{*}, \infty\right)$.

Equilibrium and parameterization. The equilibrium in the modern sector is characterized by a free entry condition (FEC) and a zero cutoff profit condition (ZCPC) as in Melitz (2003). Assuming risk neutrality, potential entrepreneurs enter the market (i.e. participate in the productivity lottery) until the value of entry $v^{E}=E\left[\sum_{t=0}^{\infty}(1-\delta)^{t} \pi(\varphi)\right\rfloor-w f_{e}$ is driven to zero (FEC). Intuitively, this condition expresses that the expected stream of profits that can be reaped in the market in the infinite lifetime is at least as high as the upfront investment $w f_{e}$. The ZCPC commands that the cutoff firm makes zero profits, $\pi\left(\varphi^{*}\right)=0$. Intuitively, since the upfront investment is sunk, firms engage in production if profits are non-negative. The equilibrium cutoff productivity $\varphi^{*}$ simultaneously satisfies the FEC and the ZCPC (appendix A). Melitz (2003) shows that such an equilibrium cutoff exists for a general class of productivity distributions. However, a closed-form solution is not obtained unless an adequate specification is chosen for the productivity distribution. We follow much of the literature in assuming Pareto-distributed productivities, $G(\varphi)=1-\left(\varphi_{\min } / \varphi\right)^{k}$ and $g(\varphi)=G^{\prime}(\varphi)=k \varphi_{\min }^{k} \varphi^{-k-1}$ where $\varphi_{\min }>0$ is the lower bound for productivity draws and $k>1$ is the shape parameter. ${ }^{6}$ Apart from allowing a closed-form solution for the cutoff, this specification has the merit to be backed by the empirics (e.g. Del Gatto et al 2006, Ikeda and Suoma 2009). The ex post

\footnotetext{
${ }^{6}$ See e.g. Bernard et al. (2003), Helpman et al. (2004), Baldwin (2005), Helpman et al. (2008) and Melitz and Ottaviano (2008).
} 
probability of productivities is then given by $\mu(\varphi)=g(\varphi) /\left[1-G\left(\varphi^{*}\right)\right]=k \varphi^{* k} \varphi^{-(k+1)}$ if $\varphi>\varphi^{*}$ and $\mu(\varphi)=0$ otherwise. It follows that $\tilde{\varphi}=[k /(k-(\sigma-1))]^{1 /(\sigma-1)} \varphi^{*}$, where we strengthen our previous assumption to $k>\sigma-1$. Using these expressions in FEC and ZCPC yields the autarky equilibrium cutoff:

$$
\varphi_{\text {aut }}^{*}=\left[\frac{(\sigma-1)}{(k-\sigma+1)} \frac{f}{f_{e}} \frac{\varphi_{\min }^{k}}{\delta}\right]^{\frac{1}{k}}
$$

Throughout the paper we assume the condition $\left([(\sigma-1) \cdot f] /\left[(k-\sigma+1) \cdot f_{e} \cdot \delta\right]\right)^{1 / k}>1$ to ensure that $\varphi_{\text {aut }}^{*}>\varphi_{\min }$. The equilibrium cutoff is independent of the number of workers $L$, positively related to the elasticity of substitution $\sigma$, the fixed labor $f$ to serve the market and the lower bound $\varphi_{\min }$, and negatively related to the fixed investment of labor at the entry stage $f_{e}$, the death rate $\delta$, as well as the Pareto-shape parameter $k .{ }^{7}$ Moreover, the autarky cutoff $\varphi_{\text {aut }}^{*}$ is unaffected by the labor coefficient in the competitive sector $a$ since this coefficient affects the wage and hence the fixed costs both to enter and serve the market equi-proportionately. Once $\varphi_{\text {aut }}^{*}$ is determined, all other endogenous variables are easily derived (appendix B). The autarky price level is $P_{\text {aut }}=(\beta L / \sigma f)^{1 /(1-\sigma)} w^{\sigma /(\sigma-1)}\left(1 / \rho \varphi_{\text {aut }}^{*}\right)$ and a household's indirect utility is then:

$$
v_{\text {aut }}=w-\beta \ln \left[\left(\frac{\beta L}{\sigma f}\right)^{\frac{1}{1-\sigma}} w^{\frac{\sigma}{\sigma-1}}\left(\frac{1}{\rho \varphi_{\text {aut }}^{*}}\right)\right]+\beta(\ln \beta-1)
$$

\section{The Open Economy}

Country asymmetries. We now turn to an open economy with two countries $i, j \in[H, F]$, say home $H$ and foreign $F$. These countries may differ with respect to country size $L_{i}$, the labor coefficient in the traditional sector $a_{i}$, technologies in the modern sector as expressed by the lower bounds $\varphi_{\min i}$ of the Pareto-distribution, exit rates $\delta_{i}$, the fixed upfront investment for entry in the modern sector $f_{e, i}$ and the fixed labor input $f_{i}$ to serve domestic markets.

Trade costs. If (after learning its productivity $\varphi_{i}$ ) a firm from country $i$ decides to export to country $j$ it faces an additional country-specific fixed cost $f_{x i}$, on top of the domestic per-

\footnotetext{
${ }^{7}$ In Melitz-Ottaviano (2008), the mark-ups on marginal costs are lower and the cutoff productivities therefore higher under autarky (and also under international trade), the greater is the domestic market size/labor force.
} 
period fixed costs $f_{i}$ that accrue irrespectively of export status. We assume that $f_{x i}>f_{i}$ to ensure that only a part of the domestic firms is active in trade. We also assume $f_{x i}>f_{j}$ so that the fixed labor input that has to be incurred to serve the export market exceeds the fixed labor that foreign competitors have to incur in their home market. Moreover, there are variable iceberg costs to serve foreign consumers: for one unit to arrive in $j$, a firm from country $i$ has to ship $\tau_{i j}>1$ units. We shall allow for the possibility that $\tau_{i j} \neq \tau_{j i}$, e.g. due to different trade policies or trade infrastructures. Trade in the traditional good is costless. As long as both countries produce this good, an assumption that we shall maintain throughout the paper, the law of one price dictates that the foreign wage is tied to the domestic wage, $W \equiv w_{F} / w_{H}=a_{H} / a_{F}$ where $W$ denotes the relative foreign wage. Note that $w_{i}=1 / a_{i}$ by our choice of the numéraire. Hence, we do not impose factor prize equalization.

Domestic and export cutoffs. The domestic cutoff productivities $\varphi_{H}^{*}$ and $\varphi_{F}^{*}$ are derived by making use of the conditions of free entry and zero cutoff profits which become interdependent in the open economy. If a firm from country $i$ exports to country $j$, its export profits are given by $\pi_{x i}(\varphi)=r_{x i}(\varphi) / \sigma-w_{i} \cdot f_{x i}$ where $r_{x i}(\varphi)=\left(\tau_{i j} w_{i} / \rho \varphi\right)^{1-\sigma} P_{j}^{\sigma-1} \beta L_{j}$ is the export revenue. There is a critical productivity threshold $\varphi_{x i}^{*}$ where such a firm breaks even on the export market, i.e. $\pi_{x i}\left(\varphi_{x i}^{*}\right)=0$. We call this the export ZCPC. Furthermore, a firm from country $i$ that serves her home market $i$ derives profits $\pi_{i}(\varphi)=r_{i}(\varphi) / \sigma-w_{i} f_{i}$ where $r_{i}(\varphi)=\left(w_{i} / \rho \varphi\right)^{1-\sigma} P_{i}^{\sigma-1} \beta L_{i}$ is the associated revenue. The $\varphi_{i}^{*}$ where this firm breaks even is defined by $\pi_{i}\left(\varphi_{i}^{*}\right)=0$. We call this the domestic ZCPC. The revenue equations imply a link between export cutoffs and domestic cutoffs, $\varphi_{x H}^{*}=W^{-\sigma /(\sigma-1)} t_{H} \varphi_{F}^{*}$ and $\varphi_{x F}^{*}=W^{\sigma /(\sigma-1)} t_{F} \varphi_{H}^{*}$ where $t_{i} \equiv \tau_{i j}\left(f_{x i} / f_{j}\right)^{1 /(\sigma-1)}$ (see appendix C). The free entry condition (FEC) for country $i$ commands that firms enter the market until the value of entry is zero, $\operatorname{prob}_{i} E\left[\pi_{i}(\varphi) / \delta_{i} \mid \varphi>\varphi_{i}^{*}\right]+\operatorname{prob}_{x i} E\left[\pi_{x i}(\varphi) / \delta_{i} \mid \varphi>\varphi_{x i}^{*}\right]=w_{i} f_{e i}$. The first term on the LHS formalizes the expected profits on the domestic market and the second term expresses expected profits on the export market where $\operatorname{prob}_{x i} \equiv 1-G_{i}\left(\varphi_{x i}^{*}\right)$ denotes the probability for a productivity draw high enough to enter the export market. The RHS expresses the entry costs.

The resulting equilibrium cutoff productivities are derived as (see appendix D): 


$$
\begin{gathered}
\varphi_{H}^{*}=\left[\frac{(\sigma-1)}{(k-\sigma+1)} \frac{f_{H}}{f_{e H}} \frac{\varphi_{\min H}^{k}}{\delta_{H}} \cdot\left[\frac{1-\Phi_{F} \Phi_{H}}{1-\Delta^{\delta, f_{e}, \varphi_{\min }, w} \cdot \Phi_{H}}\right]\right]^{\frac{1}{k}}=\varphi_{H, \text { aut }}^{*} \cdot\left[\frac{1-\Phi_{F} \Phi_{H}}{1-\Delta^{\delta, f_{e}, \varphi_{\min }, w} \cdot \Phi_{H}}\right]^{\frac{1}{k}} \\
\varphi_{F}^{*}=\left[\frac{(\sigma-1)}{(k-\sigma+1)} \frac{f_{F}}{f_{e F}} \frac{\varphi_{\min F}^{k}}{\delta_{F}} \cdot\left[\frac{1-\Phi_{F} \Phi_{H}}{1-\Phi_{F} / \Delta^{\delta, f_{e}, \varphi_{\min }, w}}\right]\right]^{\frac{1}{k}}=\varphi_{F, \text { aut }}^{*} \cdot\left[\frac{1-\Phi_{F} \Phi_{H}}{1-\Phi_{F} / \Delta^{\delta, f_{e}, \varphi_{\min }, w}}\right]^{\frac{1}{k}}
\end{gathered}
$$

where $\Phi_{i} \equiv \tau_{i j}^{-k}\left(f_{j} / f_{x i}\right)^{(k-\sigma+1) /(\sigma-1)}$ are measures of trade openness which rise as variable trade costs $\tau_{i j}$ and/or the fixed cost ratio $f_{x i} / f_{j}$ fall. Notice that $f_{x i}>f_{j}$ entails $0 \leq \Phi_{i}<1$. The parameter $\Delta^{\delta, f_{e}, \varphi_{\min }, w} \equiv D F_{e} T^{k} W^{\sigma k /(\sigma-1)}$ captures international differences (ratios) concerning exit rates $D \equiv \delta_{F} / \delta_{H}$, entry investments $F_{e} \equiv f_{e F} / f_{e H}$, technologies in the manufacturing sector as proxied by the lower productivity bounds of the Pareto-distribution $T \equiv \varphi_{\min H} / \varphi_{\min F}$ and wage differentials $W \equiv w_{F} / w_{H}=a_{H} / a_{F}$ caused by productivity differences in the competitive sector. Note that $\Delta^{\delta, f_{e}, \varphi_{\min }, w}$ rises when home business conditions turn in favor of domestic firms.

Parameter restrictions. We impose three parameter conditions on the open economy. First, we want to ensure that both sectors are active in both countries, $M_{i}>0$ (non-specialization in production), both before and after trade. This is the case whenever $\Phi_{F} \cdot(\lambda+1) /\left(\lambda+\Phi_{H} \Phi_{F}\right)<\Delta^{\delta, f_{e}, \varphi_{\min }, w}<\left(1+\lambda \Phi_{H} \Phi_{F}\right) /\left[\Phi_{H} \cdot(1+\lambda)\right]$ where $\lambda \equiv L_{H} / L_{F}$ denotes the labor endowment ratio across countries (see Appendix F). Second, in equilibrium the export cutoffs have to exceed the domestic cutoffs, $\varphi_{x i}^{*}>\varphi_{i}^{*}$, so that, in line with the empirics, only domestically active firms can export. This is guaranteed by the assumption $\left(1+f_{F} / f_{x F}\right) \cdot \Phi_{F} /\left[1+\Phi_{H} \Phi_{F} \cdot\left(f_{F} / f_{x F}\right)\right]<\Delta^{\delta, f_{e}, \varphi_{\min }, w}<\left[1+\Phi_{H} \Phi_{F} \cdot\left(f_{H} / f_{x H}\right)\right] /\left[\Phi_{H} \cdot\left(1+f_{H} / f_{x H}\right)\right]$. And third, it must hold true that $\varphi_{i}^{*}>\varphi_{\min , i}$. It can be verified that the third condition is implied by the first and the second condition. Intuitively, the parameter restrictions imply that the overall business conditions in the modern sector of the two countries must not be too different.

Trade balance and open economy equilibrium. To complete the characterization of the open economy equilibrium we have to impose balanced trade. This allows us to derive the masses of firms and the CES price indices $P_{i}=\left(\beta L_{i} / \sigma_{i}\right)^{1 /(1-\sigma)} w_{i}^{\sigma /(\sigma-1)}\left(\rho \varphi_{i}^{*}\right)^{-1}$ (see appendix E). The indirect utility then follows as: 


$$
v_{i}=w_{i}-\beta \ln \left[\left(\frac{\beta L_{i}}{\sigma f_{i}}\right)^{\frac{1}{1-\sigma}} w_{i}^{\frac{\sigma}{\sigma-1}}\left(\frac{1}{\rho \varphi_{i}^{*}}\right)\right]+\beta(\ln \beta-1)
$$

\section{$4 \quad$ Policy analysis}

\subsection{Gains from trade and trade liberalization with identical countries}

Our model deviates from the seminal contribution by Melitz (2003) in several ways: First, he used a one-sector increasing returns economy ('modern sector') whereas we consider a two sector economy which adds a traditional sector. Second, we consider an extensive list of country asymmetries. And finally, Melitz leaves the productivity lottery unspecified, whereas our analysis, for simplicity and tractability, draws on a Pareto distribution. ${ }^{8}$

However, we can replicate Melitz's central (qualitative) results even in our two-sector economy, once we assume that the countries under consideration are identical. Abstracting from all country differences (such that $\Delta^{\delta, f_{e}, \varphi_{\min }, w}=1$ and $\Phi_{H}=\Phi_{F}=\Phi$ ) and normalizing the labor productivity in the traditional sector to be $a_{i}=a_{j}=1$, we have $w_{i}=w_{j}=1$. The cutoffs under trade, eq. (9), immediately become $\varphi_{i}^{*}=\varphi_{i, \text { aut }}^{*}(1+\Phi)^{1 / k}$ both for $H$ and for $F$. Since $\Phi>0$, it is immediately clear that the cutoff under trade exceeds the cutoff under autarky, $\varphi_{i}^{*}>\varphi_{i, \text { aut }}^{*}$ which entails that the switch from autarky to trade implies a welfare benefit - the gains from trade. Moreover, a liberalization of trade costs (i.e. increasing the trade freeness $\Phi$ ), yields an increase in the cutoff, $d \varphi_{i}^{*} / d \Phi>0$ which implies that (reciprocal) trade liberalization yields welfare benefits.

Underlying these positive welfare effects is the aggregate productivity effect identified by Melitz. Both the switch from autarky to trade and the liberalization of trade lead to market entry of firms which reduces the demand for each producer and thereby drives the least productive firms out of business. This selection process raises the cutoff productivity, the aggregate productivity and the consumer's welfare. ${ }^{9}$

\footnotetext{
${ }^{8}$ The Melitz (2003) model, of course, is easily reformulated with the Pareto specification (Baldwin 2005).

${ }^{9}$ This process is similar to the 'competition effect' known in the New Economic Geography (e.g. Baldwin et al. 2003) as the reduction of demand associated with the market entry of firms works through a fall in the price level (see eq. (2), the price level $P$, which falls, when the mass of firms rises and remember that $\left.q(z)=p(z)^{-\sigma} P^{\sigma-1} \beta L\right)$. In the original Melitz (2003) model where the wage is normalized to one and where no traditional sector exists, this fall in the price level amounts to an increase in the real wage $1 / P$ which is why this process can also be thought of as working through the domestic factor market. Note, that this effect (however it may be termed) is distinct from
} 


\subsection{The technology potential and its consequences}

International productivity differences are a classic topic in international economics ever since Ricardo's (1821) reflections On the Principles of Political Economy and Taxation. Altogether new and different insights arise when technological asymmetries across countries are allowed for in models with heterogeneous firms, however. The seminal contribution by Demidova (2008) highlights differences in the technology potential in the sense that the 'productivity lottery' in one country stochastically dominates another country's lottery, or, to put it more prosaically, that firms, upon making an upfront entry investment, in some countries have access to a better pool of technologies than in other countries. Like Melitz (2003), Demidova (2008) departs from a general distribution of the 'productivity lottery'. Of course, the essence of her analysis can also be conveyed by working with the Pareto specification of the productivity lottery. More specifically, we assume that one country, say $H$, disposes of a better technology potential in the heterogeneous sector in the sense that the minimal productivity draw exceeds the minimal productivity draw in country $F$, i.e. $\varphi_{\min H}>\varphi_{\min F} \cdot{ }^{10}$

Abstracting from all other country asymmetries and assuming $\varphi_{\min H}>\varphi_{\min F}$ her main insights are easily portrayed in our model. From eq. (5) it is immediately clear that the productivity cutoff is higher in country $H$ as compared to country $F$, and, hence, so is country $H$ 's welfare level. For the open economy we now have $\Delta^{\delta, f_{e}, \varphi_{\min }, w}=T^{k}=\left(\varphi_{\min H} / \varphi_{\min F}\right)^{k}$ and $\Phi_{H}=\Phi_{F}=\Phi$ so that the cutoffs, eq. (7), are given by $\varphi_{H}^{*}=\varphi_{H, \text { aut }}^{*} \cdot\left[\left(1-\Phi^{2}\right) /\left(1-T^{k} \cdot \Phi\right)\right]^{1 / k}$ and $\varphi_{F}^{*}=\varphi_{F, a u t}^{*} \cdot\left[\left(1-\Phi^{2}\right) /\left(1-\Phi / T^{k}\right)\right]^{1 / k}$, respectively. A comparison with eq. (5) reveals that despite differences in technology potentials both the 'laggard country' $(F)$ and the 'leading' country $(H)$ achieve gains from trade. ${ }^{11}$

An intriguing new insight emerges when a unilateral improvement in the technology potential in one country (say $H$ ) takes place. This immediately entails $d \varphi_{H}^{*} / d T>0$ and $d \varphi_{F}^{*} / d T<0$. Intuitively, a unilateral improvement in the technology potential of country $i$ raises the profitability of the domestic market and gives local firms a competitive edge over their foreign competitors. This stimulates entry in country $i$ and reduces the incentive to enter the modern industry in country $j$. The induced selection effect then leads to higher cutoffs and welfare in $i$

the pro-competitive effect that arises in models where the mark-up over marginal costs is non-constant and is reduced when more firms enter the market (see Ottaviano et al. 2002 and Melitz and Ottaviano 2008).

${ }^{10}$ This special case has also been analyzed by Falvey et al. (2011) and by Melitz and Ottaviano (2008).

${ }^{11}$ Note that the parameter restrictions from section 3 still hold. Hence, the multiplicative terms of the international cutoffs are greater than one and the national cutoff productivities under trade greater than under autarky. 
and lower cutoffs and welfare in $j$. Productivity improvements are thus a boon for the country where these improvements take place but they are a bane for the other country. ${ }^{12}$

What is the welfare effect of symmetric trade integration if the two countries differ with respect to their technology potential but are identical in all other respects? Exploring the effect of $d \Phi_{H}=d \Phi_{F}=d \Phi$ on the two countries' cutoffs and indirect utilities leads to the conclusion that immiserization in the technologically inferior country would occur iff $\Delta^{\delta, f_{e}, \varphi_{\min }, w}<(2 \Phi) /\left(1+\Phi^{2}\right)$ or $\Delta^{\delta, f_{e}, \varphi_{\min }, w}>\left(1+\Phi^{2}\right) /(2 \Phi)$. However, these cases are ruled out in our model specification by the parameter restrictions we made to obtain a consistent analysis. More precisely, the parameter conditions for immiserization are also the conditions under which the 'laggard country' becomes fully specialized in the traditional good sector. Hence, we can conclude for our model specification that symmetric trade liberalization by necessity improves welfare in both countries. ${ }^{13}$ Yet, drawing on Pflüger and Russek (2011a) we shall show and explain below that immiserization becomes a distinct possibly if the two countries differ in further business conditions, notably if they differ in size and market accessibility (see section 4.5).

\subsection{Entry subsidies and welfare}

An entrepreneur who is about to start business is faced with sunk costs related with the research and development of new products and with legal barriers to entry such as licenses and permits. However, governments also provide numerous programs of support for the foundation of new firms. Such subsidies to market entry and R\&D are very widely used. Unlike classical trade policy instruments such as import tariffs or export subsidies these policies are perceived as largely domestic issues and therefore not scrutinized by bodies like the WTO.

Taking these observations as starting point, Pflüger and Südekum (2009) explore the implications of entry subsidies in the two-sector model that we laid out in sections 2 and 3 . Governments unconditionally provide entry subsidies $s$ which reduce the entry costs for (potential) firms from their raw level $f_{e}$ to the effective level $\tilde{f}_{e} \equiv f_{e}-s$. These subsidies are financed by a lump-sum tax $t$ levied at the household level. The government budget constraint is then given by $t \cdot L=s \cdot M^{E}$. Governments are assumed to be benevolent. They choose their

\footnotetext{
${ }^{12}$ This qualitative finding was also found by Melitz and Ottaviano (2008).

${ }^{13}$ Demidova (2008, proposition 1) provides an intuitive argument that in her analysis which uses a Cobb-Douglas upper tier utility and a general distribution of firm productivities such immiserization might possibly occur in the laggard country in the absence of specialization. In contrast to Demidova (2008), Melitz and Ottaviano (2008) show for their alternative framework that symmetric trade integration leads to mutual increases in productivity and welfare which is in line with our finding.
} 
policy such that the indirect utility of households $v$ is maximized subject to the government budget constraint. In the following we will look at the base case where countries are assumed to be identical with the exception of possible differences in entry subsidies. ${ }^{14}$

Starting with the autarky case, the optimal entry subsidy is immediately derived as $s_{\text {aut }}^{*}=f_{e} / \sigma$. This subsidy is positively related to the raw level of entry costs $f_{e}$ and negatively to the elasticity of substitution $\sigma$. To gain an intuitive understanding of this result it is worthwhile to reflect on the market distortions that prevail in our two-sector economy. ${ }^{15}$ There is in fact one distortion, the monopoly power of firms in the modern sector relative to the perfectly competitive traditional sector. Output is too low in the modern sector since prices are too high as indicated by the parameter $\sigma$ which determines the mark-up on marginal costs (see eq. (3)). This monopoly distortion provides the intuition for the negative relationship between $s_{a u t}^{*}$ and $\sigma$. The larger this distortion, the stronger is the incentive to subsidize. This is because an entry subsidy leads to firm entry, tougher competition and a higher cutoff, i.e. a selection effect which implies that the firms that remain in the market are more productive. However, the optimal entry subsidy that we reported above is just a second-best optimal policy. A direct way to target this distortion would be to subsidize consumption (or, alternatively, production) of the differentiated varieties. Pflüger and Südekum (2009) show that if the government had two instruments at its disposal, a consumption subsidy and an entry subsidy, the optimal policy would be to subsidize consumption at the rate $1 / \sigma$. The positive relationship between $s_{\text {aut }}^{*}$ and $f_{e}$ follows the same logic as above: a reduction in the raw entry costs tightens the welfareenhancing selection, so that the second-best optimal entry subsidy is smaller.

Policies that target the entry of firms are highly pervasive, in practice. Hence, even though they are second-best, it is very important to understand their implications. This holds a fortiori for the open economy. Suppose we have two identical countries (such that $\Delta^{\delta, f_{e}, \varphi_{\min }, w}=1$ and $\left.\Phi_{H}=\Phi_{F}=\Phi\right)$ which competitively choose their optimal entry subsidies. Each country takes the entry subsidy of the other country as given and a Nash equilibrium can then be determined. Before proceeding to this Nash equilibrium note that an exogenous decrease of the entry costs in one country (say $H$ ) raises the cutoff productivity in $H$ and lowers the cutoff productivity in $F$ (see eq. (7)). Intuitively, the increased competition and selection induced by the entry

\footnotetext{
${ }^{14}$ Pflüger and Südekum (2009) show that the basic insights carry over to a setting with further country asymmetries, notably country size.

${ }^{15}$ Note that a one-sector version of the model of monopolistic competition does not exhibit this distortion; see e.g. Demidova and Rodriguez-Clare (2009).
} 
subsidies is transmitted to the other country. Export market entry becomes more difficult for foreign enterprises, as domestic firms are now more productive and competitive. Hence, the foreign country experiences a negative selection effect, a welfare-reducing fall in its productivity cutoff.

The Nash equilibrium subsidy can straightforwardly be calculated as $s^{*}=\left[f_{e}(1-\Phi)(1+\Phi(\sigma-1))\right] /[\sigma+\Phi(\sigma-2)]$. A detailed inspection of $s^{*}$ reveals that, for the case $\sigma>2$, on which we focus, there is a bell-shaped relation between this subsidy and the parameter of trade freeness $\Phi$. If trade costs are prohibitive, $\Phi=0$, the Nash subsidy is $s^{*}=f_{e} / \sigma$. It then rises in $\Phi$, reaches a peak and falls thereafter continuously. At $\Phi=(\sigma-2) / \sigma$ it reaches $s^{*}=f_{e} / \sigma$ again and it approaches $s^{*}=0$ when trade is completely costless, $\Phi=1$. Pflüger and Südekum (2009) also derive the optimal cooperative entry subsidy which maximizes welfare (indirect utility) in both regions jointly. Intuitively, this optimal cooperative subsidy coincides with the optimal entry subsidy under autarky, $f_{e} / \sigma$. Comparing the non-cooperative (Nash) solution with the cooperative subsidy then reveals that these policies coincide at $\Phi=0$ and at $\Phi=(\sigma-2) / \sigma$ but that there is over-subsidization for the range $0<\Phi<(\sigma-2) / \sigma$ and under-subsidization for the range $(\sigma-2) / \sigma<\Phi<1$.

What is the reason for this non-monotonic effect of trade liberalization on the Nashequilibrium-subsidies? This question can be approached from two perspectives. First, we can look at the marginal benefits and marginal costs associated with these policies. The marginal benefit is the tighter selection process in the domestic market which gives domestic firms a competitive advantage in international trade. The marginal costs are that higher entry subsidies have to be financed by higher lump-sum taxes. Both marginal benefits and marginal costs can be shown to rise with the level of trade freeness. However, starting at autarky, marginal benefits rise more strongly at low levels of trade freeness than marginal costs whereas the opposite holds true for high levels of trade freeness. Intuitively, high entry subsidies are particularly attractive at high trade costs, since the firms that emerge as domestic exporters are highly productive and snatch substantial market shares from their rivals. However, when trade costs are low, there are already many domestic exporters and their productivity advantage compared to local (foreign) firms is smaller. Financing the entry subsidy is then also more costly as many entrepreneurs are induced to start up business without yielding a strong competitive edge vis-à-vis the foreign rivals. A second perspective looks at the international externalities that are associated with entry subsidization in open economies. There is the negative (inverse) selection effect that drives down the cutoff in the other economy. However, there is also a positive spillover in that the 
foreign budget is relaxed as the number of foreign firms trying to enter falls. Netting out these externalities gives the result that the net externality is negative for low levels of trade freeness and high for high levels of trade freeness, rationalizing the results of over- und undersubsidization, respectively. These results imply that there are gains from policy cooperation such that the net-externality is internalized. Importantly, whether such a cooperation involves a decrease or increase of the subsidy rates depends crucially on the level of trade freeness. In particular, a complete joint removal of all entry subsidies would lead to a welfare loss.

\subsection{Improving the research infrastructure}

Another widely observed policy in developed economies is the financing of R\&D both in direct form of public research projects and higher education and in indirect form by e.g. subsidising private research and development or installing innovation funds. Bohnstedt, Schwarz and Südekum (2011) document per capita R\&D spending in constant US-\$ for 21 OECD countries in the years 2000 and 2007/08. The United States (381,3 \$) and the Nordic countries (Norway 355,5 \$, Sweden 352,8 \$ and Finland 334,1 \$) are the leaders in 2007/2008 and they have experienced substantial increases from 2000 on. Only for two countries, Japan and the Netherlands, have these expenditures fallen. The weighted average has risen from $232,5 \$$ to $286,9 \$$.

As with entry subsidies, little was known about the effects of international trade on the choice of public research and development expenses. Bohnstedt, Schwarz and Südekum (2011) shed light on the issue by making use of the simple two sector model of section 3 . They assume that governments levy a lump-sum tax to finance basic research which is assumed to have the effect of raising the technological potential of a country as expressed by the minimum productivity draw $\varphi_{\min i}$ of the Pareto distribution as in section 4.2. After assuming a simple concave specification between a country's tax income and its level of basic research on the one hand, and choosing a simple specification between the level of basic research and the minimum productivity draw $\varphi_{\min i}$ the analysis proceeds similarly as in Pflüger and Südekum (2009).

Bohnstedt, Schwarz and Südekum (2011) identify two motives for public research policies. The 'benevolent' motive is to tighten firm selection which raises average productivity, reduces the average consumer price in an economy and increases welfare. This effect is similar to the effect of entry subsidies and becomes already clear in the autarky scenario as the domestic cutoff rises with the technological potential (see eq. (5)). In open economies there also is a strategic motive. 
If one country invests more than the other, its firms obtain a competitive advantage over their foreign competitors for similar reasons as in the previous section. Firms from the 'laggard country' now face tougher import competition and have greater difficulties to export their products. In terms of our model above, we would find that $T \equiv \varphi_{\min H} / \varphi_{\min F}$ changes by asymmetric investments into basic research, which alters the cutoffs of the two countries (see eq. (7)). If countries decide non-cooperatively on the volume of research investments, they overinvest as they do not take into account the negative cross-country externality which they exert on each other. Thus there are welfare gains by supranational policy cooperation.

Bohnstedt, Schwarz and Südekum (2011) then go on by allowing the possibility of crosscountry R\&D spillovers, i.e. a positive technological externality. Investments into basic research in one country then do not only increase the domestic but also the foreign technology potential. In terms of our model, we can express spillovers by $\varphi_{\min i}=f\left(\varphi_{\min j}\right)$ where $f(\bullet)$ is an increasing function in its argument. This positive cross-country externality (partially) offsets the negative competition externality such that the overinvestment problem is mitigated. If these $R \& D$ spillovers are sufficiently strong, the overinvestment problem might even turn into an underinvestment problem. In the light of recent research which shows that spillovers are highly localized (see e.g. Keller 2004), we would deem the latter outcome as rather unlikely, however.

\subsection{Business Conditions}

Business conditions, in practice, depend on many more factors than those we have considered in previous sections. This observation is the starting point of the analysis by Pflüger and Russek (2011a). They consider a comprehensive set of factors that determine the conditions to do business as laid out in section 3 and they focus on the impact of trade and industrial policies on national productivities and welfare.

With respect to the shift from autarky to international trade, it becomes immediately apparent from an inspection of the cutoffs in eq. (7) that both countries reap welfare gains from trade even if they are asymmetric with respect to a variety of national business conditions. Moreover, even in the case where business conditions are so disparate that the 'laggard' country is driven into full specialization in the traditional industry by the shift from autarky to trade, and where consequentially all manufactures are produced in the 'leading' country, there are mutual gains from trade. ${ }^{16}$

\footnotetext{
${ }^{16}$ The specialization model is laid out in Pflüger and Russek (2011a).
} 
Concerning the impact of bilateral trade integration, Pflüger and Russek (2011a) show that a symmetric reduction in trade costs (i.e., $d \Phi_{H}=d \Phi_{F}>0$ ) leads to welfare gains in both countries iff aggregate international business conditions (as measured by $\Delta^{\delta, f_{e}, \varphi_{\min }, w}$ ) are similar as indicated by the range $\left(\Phi_{H}+\Phi_{F}\right) /\left(1+\Phi_{H}^{2}\right)<\Delta^{\delta, f_{e}, \varphi_{\min }, w}<\left(1+\Phi_{F}^{2}\right) /\left(\Phi_{H}+\Phi_{F}\right)$. Otherwise, the country which is the 'laggard' in terms of aggregated business conditions experiences welfare losses whereas the 'leader' reaps welfare gains. Hence, while we have shown that differences in technology potentials do not suffice to obtain immiserization of the 'laggard', such immiserization becomes a distinct possibility once we account for asymmetric business conditions in a much more comprehensive sense. This becomes evident by noting that $\Delta^{\delta, f_{e}, \varphi_{\min }, w} \equiv D F_{e} T^{k} W^{\sigma k /(\sigma-1)}$ can deviate from unity even if $T \equiv \varphi_{\min H} / \varphi_{\min F}=1$, indicating identical technology potentials. ${ }^{17}$ Furthermore, note that with differences in country size and market accessibility the parameter range of non-immiserization no longer coincides with the condition of non-specialization. Hence, in contrast to section 4.2., immiserization of the 'laggard' is a possible outcome (appendix F provides a numerical example).

The effect of bilateral trade integration can be decomposed into two unilateral trade integration measures. Unilateral trade integration is understood as an opening of a country's border for products from its trading partner without an equivalent measure on behalf of its trading partner (e.g., $d \Phi_{H}>0$ whereas $d \Phi_{F}=0$ ). A unilateral border opening facilitates export activities of foreign firms which tightens competition abroad and increases the cutoff and the level of welfare of the trading partner. The liberalizing country, instead, faces tougher import competition so that the domestic cutoff and the domestic level welfare of decrease. ${ }^{18}$

Concerning the effects of industrial policies, Pflüger and Russek (2011a) provide a considerable generalization of the finding that productivity improvements in one country hurt the other country as shown by Demidova (2008). In fact, it follows immediately from the cutoffs (7) and the indirect utility (8) that the very same result holds with respect to comparative advantages due to lower wages, a lower exit risk and easier market entry. ${ }^{19}$ Importantly, asymmetric effects on productivities and on welfare obtain in the two countries even if technology potentials are identical between countries. Furthermore, policy measures are sensitive with respect to the level

\footnotetext{
${ }^{17}$ Note that differences in country size are inconsequential as was already found in Baldwin and Forslid (2006) and Baldwin (2005). However, these authors concluded that symmetric trade integration must raise welfare in both countries. The difference to our findings can be explained by noting that the authors did neither account for differences in technology potentials nor the comprehensive set of business conditions that we highlight.

${ }^{18}$ This qualitative finding was anticipated by Melitz and Ottaviano (2008).

${ }^{19}$ Differences in $f_{i}$ have an additional effect on productivities as they alternate the relative access of foreign firms to the domestic market (as $\Phi_{i} \equiv \tau_{i j}^{-k}\left(f_{j} / f_{x i}\right)^{(k-\sigma+1) /(\sigma-1)}$ ). See Pflüger and Russek (2011a) for more details.
} 
of trade integration. The smaller are trade costs, the greater is the impact on productivities and, hence, welfare. This result mimics what has previously been obtained in models of the new trade theory and the new economic geography with homogeneous firms (cf. Helpman and Krugman 1985; Baldwin et al. 2003) and the underlying mechanism is the same in both settings (see also Ossa 2011).

\subsection{A re-examination of the exit process}

Following Melitz (2003) we assumed in section 2 that the exit risk of mature firms (i.e. firms that successfully entered the market after drawing their productivity) is given by the constant exogenous probability of firm death $\delta$ and therefore independent of the productivity of the firm. The merits of this simplification are twofold. First, it facilitates the establishment of a steady state equilibrium where the productivity range, and hence the average productivity, of surviving firms is endogenously determined (Melitz 2003:1701). Second, if the group of firms whose entry is not successful is taken into account, the model is in accord with the robust empirical finding, that new entrants have, on average, lower productivity and higher exit probability than incumbents (Melitz 2003:1701), or, seen from a different angle, exiting firms have a lower productivity, on average, than surviving firms (Redding 2011: 6).

The model of section 2 has the further implication that the overall exit rate in the economy is positively related to the equilibrium cutoff productivity. Put differently, the higher is the equilibrium cutoff productivity of an economy and, hence, the average productivity of its firms in the market, the higher the exit rate. This becomes clear as the number of exiting mature firms in each period is given by $\delta \cdot M$ and the number of unsuccessful entrants is $G\left(\varphi^{*}\right) \cdot M^{E}$. Adding these up and recognizing that in the steady state $\delta \cdot M=\left[1-G\left(\varphi^{*}\right)\right] \cdot M^{E}$, it follows that the overall number of exiting firms is $M^{E}$. No matter whether we define the overall exit rate as $M^{E} / M$ or as $M^{E} /\left(M+M^{E}\right)$ our claim is easily verified. ${ }^{20}$ Since the death rate of mature firms is constant, this implication for an economy's overall exit rate is purely driven by the negative correlation between the cutoff productivity and the exit of failing business start-ups, i.e. firms dying young. Even though it has hard to come by with solid comparable international data, this positive correlation appears to be in line with the available data. ${ }^{21}$

\footnotetext{
${ }^{20}$ Under the assumption of a Pareto distribution $M^{E} / M=\delta \cdot\left(\varphi^{*} / \varphi^{\min }\right)^{k}$ which rises in $\varphi^{*}$. The same holds true for $M^{E} /\left(M+M^{E}\right)$.

${ }^{21}$ The non-availability of comparable cross-country data on firm exits is a crucial problem. Although great efforts have been made to develop comparable statistics on firm dynamics in many countries in recent years (see Dunne et al. 2009 or Bartelsmann et al., 2009), these efforts have largely been independent, however. Hence, the data reflect
} 
However, all its merits notwithstanding, the assumption of a constant exogenous death probability for mature firms is very strong (Redding 2010:6). In particular, the assumption sits very uncomfortably with the facts. Concerning mature firms, the empirical evidence strongly suggests that less productive firms are much more likely to exit markets than more productive ones. This finding has consistently been obtained for a large number of countries in many studies. Apparently, more productive firms dispose of greater ability to adapt to their environment and to make higher profits and, hence, have a greater buffer against adverse shocks. Moreover, using the perceived risk of insolvency in countries as proxy for the average death rate of mature firms a cross-country comparison suggests a negative correlation between the average death rate of mature firms and the average productivity of firms (see Pflüger and Russek 2011b). This negative relationship is clearly at odds with Melitz (2003).

Moreover, a nascent literature suggests that policies and institutions affecting the business climate in a broadly defined way are central for the understanding of firm dynamics, and so in particular for business exits (Bartelsmann et al. 2009). This literature makes clear that business conditions, i.e. the legal and institutional framework for doing business, a country's infrastructure and microeconomic policies, macroeconomic factors, and also a country's embedment into world trade are important determinants of producer dynamics and should explicitly be taken into account.

Pflüger and Russek (2011b) provide a model which takes these aspects into account. The key element of their analysis is to assume that the default risk on the level of the firms is inversely related to the firm's productivity such that $\delta=\delta(\varphi)$ and $\delta^{\prime}(\varphi)<0$. Their analysis holds for general specifications of the productivity lottery $g(\varphi)$ and of the relationship $\delta(\varphi)$. For ease of exposition, we assume a Pareto distribution of firm productivities and we work with the simple specification, $\delta(\varphi)=1 / \varphi$, in the following. Three types of average exit rates can then be derived for a steady state (see Pflüger and Russek 2011b for details). The average death rate of mature firms is given by $[(k-1) / k] \cdot \varphi^{*-1}$, the average death rate of start-ups (entrants) follows as $[(k-1) / k] \cdot\left\lfloor\varphi^{* k-1} / \varphi_{\min }^{k}-\varphi^{*-1}\right\rfloor$ and the overall average death rate is $[(k-1) / k] \cdot\left\lfloor\varphi^{* k-1} / \varphi_{\min }^{k}\right\rfloor$. The cutoff productivity $\varphi^{*}$ is key for all three concepts of average death rates: both the average death rate of entrants and the overall average death rate are positively linked to the cutoffproductivity $\varphi^{*}$ whereas the average death rate of mature firms is negatively correlated with $\varphi^{*}$.

strong country idiosyncrasies. For example, in contrast to Germany, countries like Spain, Italy and Greece do not embrace small enterprises in their statistics. Moreover, in these Mediterranean countries firms often choose less formal and juridical ways to deal with bankruptcy which are also not included in the data (e.g., a settlement or a moratorium, see CreditReform 2007, 2009). Hence their insolvency rates are strongly biased downwards. 
Solving the model with $\delta=\delta(\varphi)$ allows Pflüger and Russek (2011b) to derive sharp predictions concerning how key factors shape a country's business and trade environment and, therefore, impact on the average exit risk of firms. We look at the implications for the average death rates of mature firms in the following. ${ }^{22}$ First, the expected risk of business exit falls when a country moves from autarky to trade. Intuitively, trade opening induces a competition effect which drives up the productivity threshold to survive and hence the average productivity of firms. The country-specific exit risk falls as firms become more productive on average. Second, the effect of trade integration on the country-specific exit risk depends on the liberalization path and on the country's business conditions relative to those of its trading partners. More specifically, a country that opens up unilaterally and grants foreign firms better access to its consumers experiences an increase in its rate of firm death whilst the average firm death risk in the trading partner country falls. A symmetric trade integration path reduces the exit risk in the two countries if and only if the business conditions in these countries are similar. As soon as one country has significantly better business conditions on average (we make this concept precise in our theoretical analysis), this country experiences a fall in its default risk while the risk of business exit rises in the other country. Third, turning to the effects of business conditions for a given state of trade integration, we show that a country's exit risk is independent of the size of its population and the size of its trading partner. The country specific exit risk rises when entry investments in this (the other) country rise (fall), when its (the other country's) technical potential falls (rises) and when wage costs in this (the other) country rise (fall). The effect of an increase in the fixed investments necessary to supply the domestic market (i.e. for a distribution or retailing network, the costs of contract enforcement or corruption expenditures) on a country's default risk is to decrease the risk of firm death if trade is sufficiently costly, whilst the exit risk in the other country unambiguously falls. A cursory look at the data involving the perceived insolvency risk as in figure 1 reveals that for this group of European countries these predictions are consistent with the observations (Pflüger and Russek 2011b). Clearly, solid econometric work is needed to go beyond the simple correlations reported in that paper. The causality issue needs to be addressed, in particular. Moreover, further and better data involving a much broader sample of countries are desirable, too. The simple model specification discussed in this section appears to be an adequate starting point for deeper empirical investigations, however.

\footnotetext{
${ }^{22}$ This analysis focuses on the long-run steady state equilibrium and thereby abstracts both from the business cycle as well as from short-run adjustment processes.
} 


\section{Conclusion}

Using a simple two-sector model of monopolistic competition in the spirit of the new trade theory as a unifying framework, this paper has synthesized recent research which started to explore economic policy implications of the theories of heterogeneous firms and trade. Key lessons of this research are the following. First, there are gains from trade even if the countries under consideration differ in the conditions of doing business. Second, differences in technology potentials have strong asymmetric effects for trading partners in the sense that the leading countries win and lagging countries lose in welfare terms. Third, seemingly domestic policies such as subsidies to entry or subsidies to $R \& D$ have strong international repercussions. Non-cooperatively chosen policies typically deviate from optimal cooperative policies in nontrivial ways, so that there is scope for welfare-improving policy coordination. Fourth, symmetric trade liberalization may lead to immiserization in the country with inferior business conditions. Fifth, a re-examination of the exit process of firms which takes into account that more productive mature firms are less likely to die, delivers new insights for the average rate of firm death at the country level. The analytical ease with which the model can be employed to address country asymmetries should make it an attractive tool to study other policy issues such as policy competition in further instruments, multi-country extensions to address preferential trade agreements and political economy applications in future work.

\section{References}

Antràs, P., and E. Helpman (2004), Global Sourcing, Journal of Political Economy, 112: 552-580.

Baldwin, R., R. Forslid, P. Martin, G. Ottaviano and F. Robert-Nicoud (2003), Economic Geography and Public Policy, Princeton University Press

Baldwin, R. (2005), Heterogeneous firms and trade: Testable and untestable properties of the Melitz model, NBER Working Paper 11471, Cambridge (Mass.)

Baldwin, R. and R. Forslid (2006), Trade liberalization with heterogeneous firms, NBER Working Paper 12192, Cambridge (Mass.)

Bartelsman, E., Haltiwanger, and S. Scarpetta (2009), Measuring and Analyzing Cross-Country Differences in Firm Dynamics, in: Dunne, T., J.B. Jensen, and M.J. Roberts (Eds.), Producer Dynamics. New Evidence from Micro Data, University of Chicago Press, Chicago and London

Bernard, A., J. Eaton, B. Jensen and S. Kortum (2003), Plants and productivity in international trade, American Economic Review 93, 1268-1290

Bernard, A.B., J.B. Jensen, S. Redding and P. Schott (2007), Firms in International Trade, Journal of Economic Perspectives 21(3), 105-130

Bernard, A., S.J. Redding and P. Schott (2007), Comparative Advantage and Heterogeneous Firms, Review of Economic Studies 74(1), 31-66 
Bohnstedt, A., C. Schwartz and J. Südekum (2011), Globalization and Strategic Research Investments, forthcoming in: Reseach Policy

Chor, D. (2009), Subsidies for FDI: Implications from a model with heterogeneous firms, Journal of International Economics 78, 113-125

CreditReform (2007), Insolvenzen in Europa, Jahr 2006/07, Verband der Vereine Creditreform e.V., available online on www.creditreform.at

CreditReform (2009), Insolvenzen in Europa, Jahr 2008/09, Verband der Vereine Creditreform e.V., available online on www.creditreform.at

Demidova, S. (2008), Productivity improvements and falling trade costs: Boon or Bane. International Economic Review 49(4): 1437-1462

Demidova, S. and A. Rodríguez-Clare (2009), Trade policy under firm-level heterogeneity in a small economy, Journal of International Economics 78(1), 100-112.

Dixit, A. and J. Stiglitz (1977), Monopolistic competition and optimum product diversity, American Economic Review 67, 297-308

Del Gatto, M., G. Mion, and G.I.P. Ottaviano (2006), Trade integration, firm selection and the costs of non-Europe. CEPR Discussion Paper 5730

Eckel, C. and H. Egger (2009), Wage bargaining and multinational firms, Journal of International Economics, 77(2), 206 - 214

Egger, H. and U. Kreickemeier (2009), Firm Heterogeneity and the Labour Market Effects of Trade Liberalization, International Economic Review, 50(1), 187-216

Falvey, R., D. Greenaway and Z. Yu (2011), Catching up or pulling away: Intra-industry trade, productivity gaps and heterogeneous firms, Open Economies Review 22(1), 17-38

Felbermayr, G., J. Prat and H.-J. Schmerer (2011), Globalization and Labor Market Outcomes: Wage Bargaining, Search Frictions, and Firm Heterogeneity, Journal of Economic Theory, 146(1), 3973.

Flam, H. and E. Helpman (1987), Industrial policy under monopolistic competition, Journal of International Economics 22, 79-102

Helpman, E. and P. Krugman (1985), Market structure and foreign trade, Cambridge: MIT Press

Helpman, E. and P. Krugman (1989), Trade policy and market structure, Cambridge (Mass.): MIT Press

Helpman, E. (2006), Trade, FDI, and the Organization of Firms, Journal of Economic Literature 44 (3), $589-630$

Helpman, E. and O. Itskhoki (2010), Labor Market Rigidities, Trade and Unemployment, Review of Economic Studies, 77 (3), 1100-1137

Helpman, E., O. Itskhoki and S. Redding (2010), Inequality and Unemployment in a Global Economy, Econometrica, 78 (4), 1239-1283

Helpman, E., M. Melitz and Y. Rubinstein (2008), Estimating trade flows: Trading partners and trading volumes, Quarterly Journal of Economics 123: 441-487

Helpman, E., M. Melitz and S.R.Yeaple (2004), Export versus FDI with heterogeneous firms, American Economic Review 94(1), 300-316

Ikeda, Y. and W. Suoma (2009), International Comparison of Labor Productivity Distribution for Manufacturing and Non-Manufacturing Firms. Progress of Theoretical Physics Supplement No. $179,93-102$

Keller, K. (2004), International Technology Diffusion, Journal of Economic Literature 42(3), 752-782

Martin, P. and C.A. Rogers (1995), Industrial Location and Public Infrastructure, Journal of International Economics 39, 335-351 
Mayer, T. and I.M. Ottaviano (2007), Happy few: the internationalization of European firms. New facts based on firm-level evidence, Open Access publications (Sciences Po) nr: info:hdl:2441/10147.

Melitz (2003), The impact of trade on intra-industry reallocations and aggregate industry productivity. Econometrica 71(6), 1695-1725

Melitz, M. and G. Ottaviano (2008), Market size, trade, and productivity, Review of Economic Studies $75,295-316$

Ottaviano, G., T. Tabuchi and J.-F. Thisse (2002), Agglomeration and Trade Revisited, International Economic Review 43(2), 409-436

Pflüger, M. and S. Russek (2011a), Trade and Industrial Policies with Heterogeneous Firms: The Role of Country Asymmetries, revised version of IZA DP 5387

Pflüger, M. and S. Russek (2011b), Business Conditions and Default Risks Across Countries, revised version of IZA DP 5541

Pflüger, M. and J. Südekum (2009), Subsidizing Firm Entry in Open Economies, IZA Working Paper 4384

Redding, S. (2011), Theories of Heterogeneous Firms and Trade, Annual Review of Economics 3, 77105

Ricardo,D. (1821), On the Principles of Political Economy and Taxation.

Venables, A. (1987), Trade and trade policy with differentiated products: A Chamberlinian-Ricardian model, Economic Journal 97: 700-717

Yeaple, S.R. (2005), A simple model of firm heterogeneity, international trade, and wages, Journal of International Economics 65, 1-20 


\section{Appendices}

\section{Appendix A - The FEC and ZCPC condition}

Using $\pi(\varphi)=r(\varphi) / \sigma-w f \quad$ and $\quad r(\varphi)=(\varphi / \tilde{\varphi})^{\sigma-1} r(\tilde{\varphi})$ where $\tilde{\varphi} \equiv E\left[\varphi^{\sigma-1} \mid \varphi>\varphi^{*}\right]^{1 /(\sigma-1)} \quad$ is a measure of average productivity, and imposing $v^{E}=0$, the FEC can be derived as $\pi(\tilde{\varphi})=\delta w f_{e} /\left[1-G\left(\varphi^{*}\right)\right]$. Using $\pi(\tilde{\varphi})=[r(\tilde{\varphi}) / \sigma]-w f$ and $r\left(\varphi^{*}\right)=\left(\varphi^{*} / \tilde{\varphi}\right)^{\sigma-1} r(\tilde{\varphi})$, the ZCPC condition can be expressed as a function of the average productivity level $\tilde{\varphi}$ : $\pi(\tilde{\varphi})=\left\lfloor\left(\tilde{\varphi} / \varphi^{*}\right)^{\sigma-1}-1\right\rfloor w f$.

\section{Appendix B - Firm masses, the price level and indirect utility under autarky}

In equilibrium, the aggregate expenditure on manufacturing has to be equal to the aggregate revenue of manufacturing firms, $\beta L=\operatorname{Mr}(\tilde{\varphi})$. Using $r(\tilde{\varphi})=\left(\tilde{\varphi} / \varphi^{*}\right)^{\sigma-1} \sigma w f$, $\tilde{\varphi}=[k /(k-(\sigma-1))]^{1 /(\sigma-1)} \varphi^{*}$, and the equilibrium cutoff (5), the number of active firms can be derived, $M_{a u t}=\frac{\beta L[k-(\sigma-1)]}{\sigma k w f}$. The stationarity condition then implies the number of entrants, $M_{\text {aut }}^{E}=\frac{(\sigma-1) \beta L}{\sigma k w f_{e}}$. Using $M_{\text {aut }}$ and $\tilde{\varphi}=[k /(k-(\sigma-1))]^{1 /(\sigma-1)} \varphi^{*}$ in (4), yields the price level, $P_{\text {aut }}=(\beta L / \sigma f)^{1 /(1-\sigma)} w^{\sigma /(\sigma-1)}\left(1 / \rho \varphi_{\text {aut }}^{*}\right)$ and the indirect utility of a household is then as in eq. (6).

\section{Appendix C - The link between the productivity cutoffs in the open economy}

From the ZCP conditions it follows that $r_{i}\left(\varphi_{i}^{*}\right)=\left(\rho \varphi_{i}^{*} P_{i}\right)^{\sigma-1} \beta L_{i}=\sigma w_{i} f_{i}$ and $r_{x i}\left(\varphi_{x i}^{*}\right)=\left(\tau_{i j} w_{i} / \rho \varphi_{x i}^{*}\right)^{1-\sigma} P_{j}^{\sigma-1} \beta L_{j}=\sigma w_{i} f_{x i}$. Consequently, we have

$$
\begin{gathered}
\frac{r_{H}\left(\varphi_{H}^{*}\right)}{r_{F}\left(\varphi_{F}^{*}\right)}=\frac{w_{H} f_{H}}{w_{F} f_{F}} \Rightarrow \frac{\varphi_{H}^{*}}{\varphi_{F}^{*}}=W^{-\sigma /(\sigma-1)} \frac{P_{F}}{P_{H}}\left(\frac{f_{H} L_{F}}{f_{F} L_{H}}\right)^{1 /(\sigma-1)} \\
\frac{r_{x H}\left(\varphi_{x H}^{*}\right)}{r_{x F}\left(\varphi_{x F}^{*}\right)}=\frac{w_{H} f_{x H}}{w_{F} f_{x F}} \Rightarrow \frac{\varphi_{x H}^{*}}{\varphi_{x F}^{*}}=W^{-\sigma /(\sigma-1)} \frac{\tau_{H F}}{\tau_{F H}} \frac{P_{H}}{P_{F}}\left(\frac{f_{x H} L_{H}}{f_{x F} L_{F}}\right)^{1 /(\sigma-1)} \\
\frac{r_{x i}\left(\varphi_{x i}^{*}\right)}{r_{i}\left(\varphi_{i}^{*}\right)}=\frac{f_{x i}}{f_{i}} \Rightarrow \frac{\varphi_{x i}^{*}}{\varphi_{i}^{*}}=\tau_{i j}\left(\frac{f_{x i}}{f_{i}}\right) \frac{P_{i}}{P_{j}}\left(\frac{L_{i}}{L_{j}}\right)^{1 /(\sigma-1)}
\end{gathered}
$$


Combining (C1) and (C3) leads to $\varphi_{x H}^{*}=W^{-\sigma /(\sigma-1)} t_{H} \varphi_{F}^{*}$ and $\varphi_{x F}^{*}=W^{\sigma /(\sigma-1)} t_{F} \varphi_{H}^{*}$ where $t_{i} \equiv \tau_{i j}\left(f_{x i} / f_{i}\right)^{1 /(\sigma-1)}$.

\section{Appendix D: Determination of equilibrium cutoffs in the open economy}

The free entry condition (FEC) for country $i$ is given by

$$
\left(1-G_{i}\left(\varphi_{i}^{*}\right)\right) \cdot E\left[\pi_{i}(\varphi) \mid \varphi>\varphi_{i}^{*}\right]+\left(1-G_{i}\left(\varphi_{x i}^{*}\right)\right) \cdot E\left[\pi_{x i}(\varphi) \varphi>\varphi_{x i}^{*}\right]=w_{i} \cdot f_{e i} \cdot \delta_{i}
$$

As $\pi_{i}(\varphi)=r_{i}(\varphi) / \sigma-w_{i} f_{i}$, we can write the expected domestic profits as

$$
E\left[\pi_{i}(\varphi) \mid \varphi>\varphi_{i}^{*}\right]=\frac{1}{\sigma} E\left[r_{i}(\varphi) \mid \varphi>\varphi_{i}^{*}\right]-w_{i} f_{i}
$$

Using $r_{i}(\varphi)=\left(\rho \varphi / w_{i}\right)^{\sigma-1} P_{i}^{\sigma-1} \beta L_{i}$ and the Pareto specification we get

$$
E\left[\pi_{i}(\varphi) \mid \varphi>\varphi_{i}^{*}\right]=\left(\frac{r_{i}\left(\varphi_{i}^{*}\right)}{\sigma} \frac{k}{k-\sigma+1}-w_{i} f_{i}\right)
$$

On substituting $r_{i}\left(\varphi_{i}^{*}\right)=\sigma w_{i} f_{i}$ which is implied by the domestic ZCPC $\pi_{i}\left(\varphi_{i}^{*}\right)=0$, we have:

$$
E\left[\pi_{i}(\varphi) \mid \varphi>\varphi_{i}^{*}\right]=\frac{\sigma-1}{k-\sigma+1} w_{i} f_{i}
$$

The expected export profits are determined in the same manner. Now we use export profits, export revenue, the previous parameterizations as well as the export ZCPC to obtain:

$$
E\left[\pi_{x i}(\varphi) \mid \varphi>\varphi_{x i}^{*}\right]=\frac{\sigma-1}{k-\sigma+1} w_{i} f_{x i}
$$

Substituting (D2) and (D3) into (D1) and using $G_{i}(\varphi)=1-\left(\varphi_{\min i} / \varphi_{i}\right)^{k}$ yields $\frac{\sigma-1}{k-\sigma+1} \varphi_{\min i}^{k} f_{i}\left(\varphi_{i}^{*}\right)^{-k}+\frac{\sigma-1}{k-\sigma+1} \varphi_{\min i}^{k} f_{x i}\left(\varphi_{x i}^{*}\right)^{-k}=f_{e i} \cdot \delta_{i}$. Writing this equation out for $i=H, F$ and using the relationships between export cutoffs and domestic cutoffs, $\varphi_{x H}^{*}=W^{-\sigma /(\sigma-1)} t_{H} \varphi_{F}^{*}$ and $\varphi_{x F}^{*}=W^{\sigma /(\sigma-1)} t_{F} \varphi_{H}^{*}$ as derived in appendix $\mathrm{C}$ yields two equations which can be solved for the cutoffs $\varphi_{H}^{*}$ and $\varphi_{F}^{*}$ as stated in eq. (7).

\section{Appendix E: Firm masses, the price level and indirect utility under trade}

To derive the firm masses in the open economy equilibrium we have to impose balanced trade. From the perspective of the domestic economy, this condition is given by:

$$
\operatorname{cprob}_{x H} M_{H} r_{x H}\left(\tilde{\varphi}_{x H}\right)=\operatorname{cprob}_{x F} M_{F} r_{x F}\left(\tilde{\varphi}_{x F}\right)+\left(w_{H}-\beta\right) L_{H}-\left(1-\gamma_{H}\right) L_{H} / a_{H}
$$


where $\operatorname{cprob}_{x i} \equiv \operatorname{prob}_{x i} / \operatorname{prob}_{i}=\left(\varphi_{i}^{*} / \varphi_{x i}^{*}\right)^{k}$ is the conditional probability to become an exporter in country $i$ and where $\gamma_{H}$ denotes the share of labor employed in the modern sector in country $H$. The LHS of eq. (8) gives the value of country $H$ 's manufacturing exports and the first term on the RHS gives the value of manufacturing imports. The second and third term on the RHS are the values of domestic consumption and production of the traditional good, respectively. Any imbalance in trade in manufacturing must be matched by a trade surplus or deficit in this numéraire. Now use this balanced trade condition and substitute $M_{i}=\gamma_{i} L_{i} w_{i} / \bar{r}_{i}$ where $\bar{r}_{i} \equiv r_{i}\left(\tilde{\varphi}_{i}\right)+\operatorname{cprob}_{x i} r_{x i}\left(\tilde{\varphi}_{x i}\right), w_{H}=1 / a_{H}$ and $\beta\left(L_{H}+L_{F}\right)=\gamma_{H} L_{H} w_{H}+\gamma_{F} L_{F} w_{F}$. Solving for the $\gamma_{i}$ then gives:

$$
\gamma_{H}=\frac{\beta}{w_{H}} \frac{\bar{r}_{H}}{r_{H}\left(\tilde{\varphi}_{H}\right)} \frac{1-\Phi_{F} / \Delta^{L, \varphi^{*}}}{1-\Phi_{H} \Phi_{F}} \quad \text { and } \quad \gamma_{F}=\frac{\beta}{w_{F}} \frac{\bar{r}_{F}}{r_{F}\left(\tilde{\varphi}_{F}\right)} \frac{1-\Phi_{H} \cdot \Delta^{L, \varphi^{*}}}{1-\Phi_{H} \Phi_{F}}
$$

where $\Delta^{L, \varphi^{*}} \equiv \frac{f_{F}}{f_{H}} \frac{L_{H}}{L_{F}} W^{\frac{k \sigma}{\sigma-1}}\left(\frac{\varphi_{F}^{*}}{\varphi_{H}^{*}}\right)^{k}=\frac{L_{H}}{L_{F}} \frac{\Delta^{\delta, f_{e}, \varphi \min , w}-\Phi_{F}}{1-\Delta^{\delta, f_{e}, \varphi \min , w} \Phi_{H}}$ is an increasing measure of relative conditions favoring business in $H$ (against $F$ ). Using $\gamma_{i}$, the masses of firms are immediately implied by $M_{i} \bar{r}_{i}=\gamma_{i} L_{i} w_{i}$ where $r_{i}\left(\tilde{\varphi}_{i}\right)$ follows from the domestic ZCPC and is given by $r_{i}\left(\tilde{\varphi}_{i}\right)=\sigma k f_{i} w_{i} /[k-(\sigma-1)]$. Hence, we have

$$
\begin{aligned}
& M_{H}=\frac{[k-(\sigma-1)] \beta L_{H}}{\sigma k f_{H} w_{H}} \cdot\left(\frac{1-\Phi_{F} / \Delta^{L, \varphi^{*}}}{1-\Phi_{H} \Phi_{F}}\right)=M_{H, \text { aut }} \cdot\left(\frac{1-\Phi_{F} / \Delta^{L, \varphi^{*}}}{1-\Phi_{H} \Phi_{F}}\right) \\
& M_{F}=\frac{[k-(\sigma-1)] \beta L_{F}}{\sigma k f_{F} w_{F}} \cdot\left(\frac{1-\Phi_{H} \Delta^{L, \varphi^{*}}}{1-\Phi_{H} \Phi_{F}}\right)=M_{F, \text { aut }} \cdot\left(\frac{1-\Phi_{H} \Delta^{L, \varphi^{*}}}{1-\Phi_{H} \Phi_{F}}\right)
\end{aligned}
$$

The number of exporting firms is implied by $M_{x i}=\operatorname{cprob}_{x i} M_{i}$ and the mass of entrants follows according to $M_{i}^{E}=\varphi_{\min i}^{-k} \varphi_{i}^{* k} \delta_{i} M_{i}$. The consumption variety available in country $i$ is $M_{t i}=M_{i}+M_{x j}$.

With the price setting rule defined by eq. (3), the price level can be rewritten as $P_{i}=M_{t i}{ }^{\frac{1}{1-\sigma}} \cdot p_{i}\left(\widetilde{\varphi}_{t i}\right)$. The variable $\tilde{\varphi}_{t i}=\left\{\left(1 / M_{t i}\right)\left[M_{i} \tilde{\varphi}_{i}^{\sigma-1}+M_{x j}\left(w_{j} / w_{i}\right)^{1-\sigma} \tau_{j i}^{1-\sigma} \widetilde{\varphi}_{x j}^{\sigma-1}\right]\right\}^{\frac{1}{\sigma-1}}$ is an average productivity of all firms (domestic and foreign) that serve consumers in country $i$. Consumers in country $i$ spend $M_{t i} r_{i}\left(\tilde{\varphi}_{t i}\right)=\beta L_{i}$ on manufacturing varieties and the average firm revenue is related to the revenue of the cutoff firm according to $r_{i}\left(\tilde{\varphi}_{t i}\right)=\left(\tilde{\varphi}_{t i} / \varphi_{i}^{*}\right)^{\sigma-1} r_{i}\left(\varphi_{i}^{*}\right)$. With $r_{i}\left(\varphi_{i}^{*}\right)=\sigma w_{i} f_{i}$ it follows that $M_{t i}=\beta L_{i}\left(\widetilde{\varphi}_{t i} / \varphi_{i}^{*}\right)^{1-\sigma} / \sigma w_{i} f_{i}$. On substitution, this yields for 
the price level $P_{i}=\left(\beta L_{i} / \sigma f_{i}\right)^{1 /(1-\sigma)} w_{i}^{\sigma /(\sigma-1)}\left(\rho \varphi_{i}^{*}\right)^{-1}$. Notice that the derivation of the price level is independent from the derivation of the productivity thresholds and observe that it is completely general (it does not depend on the Pareto parameterization).

\section{Appendix F: Parameter restrictions}

Non-specialization: Using eqs. (E1) and imposing $M_{i} \geq 0$, both countries have manufacturing producers if $\Phi_{F}<\Delta^{L, \varphi^{*}}<1 / \Phi_{H}$. By substituting $\Delta^{L, \varphi^{*}} \equiv \lambda \cdot\left(\Delta^{\delta, f_{e}, \varphi_{\min }, w}-\Phi_{F}\right) /\left(1-\Delta^{\delta, f_{e}, \varphi_{\min }, w} \cdot \Phi_{H}\right)$, where $\lambda \equiv L_{H} / L_{F}$ is the ratio of labor endowment in $H$ relative to $F$, and solving for $\Delta^{\delta, f_{e}, \varphi_{\min }, w}$, this condition for non-specialization in both countries can be rewritten as

$$
\Phi_{F} \frac{\lambda+1}{\lambda+\Phi_{H} \Phi_{F}}<\Delta^{\delta, f_{e}, \varphi_{\min }, w}<\frac{1}{\Phi_{H}} \frac{1+\lambda \Phi_{H} \Phi_{F}}{1+\lambda}
$$

Meaningful export-cutoffs: We assume that only firms that serve the domestic market can export, i.e. $\varphi_{x i}^{*}>\varphi_{i}^{*}$. From eq. (C3) it follows that this holds true whenever $\tau_{i j}\left(f_{x i} / f_{i}\right)^{1 /(\sigma-1)}\left(P_{i} / P_{j}\right)\left(L_{i} / L_{j}\right)^{1 /(\sigma-1)}>1$. Substituting $P_{i}=\left(\beta L_{i} / \sigma_{i}\right)^{1 /(1-\sigma)} w_{i}^{\sigma /(\sigma-1)}\left(\rho \varphi_{i}^{*}\right)^{-1} \quad$ and rearranging yields $f_{x i} / f_{j}>\tau_{i j}^{1-\sigma}\left(w_{j} / w_{i}\right)^{\sigma}\left(\varphi_{i}^{*} / \varphi_{j}^{*}\right)^{\sigma-1}$. Using the equilibrium cutoffs reported in eq. (7) and solving the inequality for $\Delta^{\delta, f_{e}, \varphi_{\min }, w}$, we have meaningful export cutoffs, whenever

$$
\frac{1+f_{F} / f_{x F}}{1+\Phi_{H} \Phi_{F} \cdot\left(f_{F} / f_{x F}\right)} \cdot \Phi_{F}<\Delta^{\delta, f_{e}, \varphi_{\min }, w}<\frac{1+\Phi_{H} \Phi_{F} \cdot\left(f_{H} / f_{x H}\right)}{1+f_{H} / f_{x H}} \cdot \frac{1}{\Phi_{H}}
$$

Note that in Demidova (2008) the condition $\varphi_{x i}^{*}>\varphi_{i}^{*}$ implies $\varphi_{x i}^{*}>\varphi_{j}^{*}$ (i.e. that a domestic firm finds it easier to break even in its domestic market than a foreign exporter does) since her model assumes $W=1$. However, in the presence of a possibly large wage differential it is quite conceivable that an exporting firm might find it easier to break even than a local firm does. Hence, the implication will not carry over to our model, in general.

Linking the restrictions: To ensure that there is a range of parameters which simultaneously fulfils both inequalities we have to make sure that the lower bound of each parameter restriction is smaller than the upper bound of the other. This boils down to the necessary parameter restriction $\frac{f_{H}}{f_{x H}} \cdot \Phi_{H} \Phi_{F}<\lambda<\left(\frac{f_{F}}{f_{x F}} \cdot \Phi_{H} \Phi_{F}\right)^{-1}$. 
Numerical examples: For the reader's convenience we provide two numerical examples to illustrate that there is a broad parameter space despite the parameter restrictions made above.

Assume $\lambda=0.9, f_{H} / f_{x H}=0.8, f_{F} / f_{x F}=0.7$. A) If $\Phi_{H}=0.5$ and $\Phi_{F}=0.35$, the nonspecialization condition reads $0.62<\Delta^{\delta, f_{e}, \varphi_{\min }, w}<1.21$, the condition for meaningful export cutoff is $0.53<\Delta^{\delta, f_{e}, \varphi_{\min }, w}<1.26$ and the linking condition $0.14<\lambda<8.16$ which is fulfilled by $\lambda=0.9$. The interval for mutual gains from symmetric trade liberalization is given by $0.68<\Delta^{\delta, f_{e}, \varphi_{\min }, w}<1.21$. For $0.62<\Delta^{\delta, f_{e}, \varphi_{\min }, w}<0.68$ country $H$ loses, whereas country $F$ wins. B) If $\Phi_{H}=0.4$ and $\Phi_{F}=0.65$, the non-specialization condition is $1.07<\Delta^{\delta, f_{e}, \varphi_{\min }, w}<1.62$, the condition for meaningful export cutoff is $0.94<\Delta^{\delta, f_{e}, \varphi_{\min }, w}<1.67$ and the linking condition is $0.21<\lambda<5.49$. If $1.07<\Delta^{\delta, f_{e}, \varphi_{\min }, w}<1.35$ both countries win by symmetric trade integration. For $1.35<\Delta^{\delta, f_{e}, \varphi_{\min }, w}<1.62$ country $F$ loses, whereas country $H$ gains. 